\title{
Effects of exposure to low concentrations of carbon monoxide on exercise performance and myocardial perfusion in young healthy men
}

Yochai Adir, Amnon Merdler, Simona Ben Haim, Avi Front, Ruth Harduf, Haim Bitterman

\begin{abstract}
Objective-To assess the effects of exposure to low concentrations of carbon monoxide (CO), as commonly measured in atmospheric urban air pollution and certain occupational environments, on exercise performance and myocardial perfusion in young healthy men, and the possible need for tighter restrictions on ambient concentrations of $\mathrm{CO}$.

Methods-15 young, healthy non-smoking men, 18-35 years old, were exposed blindly and randomly to air or to a mixture of $\mathrm{CO}$ and air, followed by an exercise treadmill test with thallium heart scintigraphy. Blood was drawn for determination of carboxyhaemoglobin before and at the end of the exposure, and for lactic and pyruvic acid at the beginning and the end of the exercise test. The main outcome measures include the duration of the exercise test, the maximal effort expressed in metabolic equivalent units (METs), the mean plasma lactic to pyruvic acid ratio at the end of the ergometry, ECG changes in the exercise test, and perfusion deficits in thallium heart scintigraphy.
\end{abstract}

Internal Medicine A

Y Adir

H Bitterman

Department of Nuclear Medicine,

Carmel Medical

Center, and The

Rappaport Family

Faculty of Medicine,

Technion-Israel

Institute of Technology,

Haifa, Israel

$S$ Ben Haim

A Front

Department of Cardiology, Carmel Medical Center, Haifa, Israel

A Merdler

Department of

Nuclear Medicine,

Beilinson Medical

Center, Petah Tiqva,

Israel

R Harduf

Correspondence to: Dr Haim Bitterman, Department of Internal Medicine A, Carmel Medical Center, 7 Michal Street, 34 362 Haifa, Israel. Telephone 0097248250486 ; fax 00972 48260213.

Accepted 17 March 1999 1.52 minutes $95 \%$ confidence interval (95\% CI) 0.73 to 2.32 minutes. The mean adjusted difference of METs between exposure to air and CO was $2.0495 \%$ CI 1.33 to 2.76. The models for duration of exercise and METs showed no significant sequence and period effects. Thallium myocardial perfusion imaging disclosed normal perfusion in all regions of the heart, with no significant differences in perfusion between the two exercise tests (after air or $\mathrm{CO}$ ).
Conclusion-Acute exposure to a low concentration of $\mathrm{CO}$ which produces blood carboxyhaemoglobin concentrations of 4\%-6\% significantly decreases exercise performance in young healthy men. No ischaemic electrocardiographic changes or disturbances in myocardial perfusion were found by graded exercise with thallium scintigraphy. Our findings suggest that pollution of atmospheric air by $\mathrm{CO}$ at concentrations which are commonly found in urban and industrial environments may exert an adverse effect on skeletal muscles, manifesting as decreased exercise performance.

(Occup Environ Med 1999;56:535-538)

Keywords: carbon monoxide; exercise; ischaemia;thallium scintigraphy

Carbon monoxide (CO) poisoning is the leading cause of death from intoxication. The first symptoms of CO intoxication usually appear when the blood concentration of carboxyhaemoglobin $(\mathrm{COHb})$ rises above $10 \% .^{1}$ It is known that exposure to very high concentrations of CO can cause myocardial ischaemia and failure even in the normal heart. ${ }^{2}$ However, recent studies have reported that exposure to low concentrations of $\mathrm{CO}$ producing venous $\mathrm{COHb}$ blood concentrations of $2 \%-6 \%$ induce ischaemic changes and ventricular arrhythmias in patients with coronary heart disease. ${ }^{3-6}$ Similar low venous blood concentrations of $\mathrm{COHb}$ are commonly found in people employed in certain high risk occupations, in residents of industrial cities, and in smokers. ${ }^{2}$ The evidence of the potential hazards of exposure to low concentrations of $\mathrm{CO}$ in patients with ischaemic heart disease raises important questions about its effects in healthy humans.

The present study was designed to evaluate the short term effects of exposure to concentrations of $\mathrm{CO}$ which produce low venous blood $\mathrm{COHb}$ concentrations of $4 \%-6 \%$ on exercise performance and myocardial perfusion in young healthy men.

\section{Methods}

SUBJECTS POPULATION

All 15 subjects were volunteers who met the following criteria:

(1) Non-smoking healthy men, 18-35 years old.

(2) Normal physical examination and medical history. 
(3) Normal resting electrocardiogram and blood tests including blood count and concentrations of urea, creatinine, electrolytes, cholesterol, and triglyceride.

\section{STUDY DESIGN}

The study was performed in two stages 1 month apart. In both stages of the study each subject was randomised by a list of random numbers to exposure to room air or a mixture of $\mathrm{CO}$ and air to produce a venous blood $\mathrm{COHb}$ concentration of $4 \%-6 \%$. The exposure was performed by breathing through a closed breathing circuit connected to two gas tanks, one with room air and the other with the $\mathrm{CO}$ mixture. The randomisation was carried out by an independent person with no knowledge of the study performance. The randomisation was planned so that subjects who were exposed to room air were exposed to the $\mathrm{CO}$ mixture in the second stage and vice versa (blind crossover study). The subjects and the physician who took part in the study and study supervisors did not know whether the subjects were breathing room air or the CO mixture. The duration of the exposure required to produce the desirable $\mathrm{COHb}$ concentration was calculated according to a previously used clinical database. ${ }^{89}$ In a pretest on six other volunteers, the required duration was found to be 3 minutes 45 seconds. Blood was drawn for $\mathrm{COHb}$ concentrations before and at the end of the exposure. The $\mathrm{COHb}$ measurements were performed with a COoxymeter (IL-282). Immediately after the exposure, subjects performed an exercise treadmill test according to the Bruce protocol, at their maximal capacity to exhaustion, with thallium heart scintigraphy.

The Bruce protocol is the most commonly used multistage graded maximal treadmill protocol with consecutive periods of increasing difficulty. The duration of each stage is $3 \mathrm{~min}-$ utes to allow achievement of a steady state before the workload is increased. ${ }^{10}$ The difficulty of each stage of the Bruce protocol is characterised by metabolic equivalent units (METs). MET refers to the resting oxygen consumption $\left(\mathrm{VO}_{2}\right)$ for a $70 \mathrm{~kg}, 40$ year old $\mathrm{man}$. One MET is equivalent to $3.5 \mathrm{ml} / \mathrm{min} / \mathrm{kg}$ of body weight representing the approximate metabolic cost to stand quietly. Multiples of METs are used to calculate work activity. The METs are the most common measure used to standardise the reporting of peak exercise workload in exercise protocols. ${ }^{11}$ Heart rate, blood pressure, electrocardiogram, the duration of the exercise, and the maximum effort expressed in MET units were recorded for each exercise test. Thallium scintigraphy was performed with an Elscint camera SP-4 with a low energy all purpose collimator. The first thallium injection of $3 \mu \mathrm{Ci}$ was given at peak exer-

Table 1 Lactic and pyruvic acid concentrations (mean (SD)) before and after the exercise test

\begin{tabular}{llllll}
\hline & $\begin{array}{l}\text { Lactic to pyruvic } \\
\text { acid ratio after } \\
\text { exercise }\end{array}$ & $\begin{array}{l}\text { Pyruvic acid } \\
\text { after exercise }\end{array}$ & $\begin{array}{l}\text { Lactic acid } \\
\text { after exercise }\end{array}$ & $\begin{array}{l}\text { Pyruvic acid } \\
\text { at baseline }\end{array}$ & $\begin{array}{l}\text { Lactic acid } \\
\text { at baseline }\end{array}$ \\
\hline Exposure to air & $69.9(5.9)$ & $0.23(0.03)$ & $14.9(1.2)$ & $0.006(0.06)$ & $0.22(1.6)$ \\
Exposure to CO & $75.9(7.0)$ & $0.017(0.18)$ & $1.1(12.5)$ & $0.004(0.04)$ & $0.15(1.6)$ \\
\hline
\end{tabular}

cise, 2 minutes before the end of the ergometry. After a recovery period of 10 minutes, a tomographic scan was made of the heart with the SPECT method. ${ }^{12}{ }^{13}$ Three hours later another $1 \mu \mathrm{Ci}$ of thallium was injected (the reinjection technique), and a second scan was performed. The two scans were reconstructed in three dimensions and were compared with the normal data base. ${ }^{14}$ It was unknown to the scan reader whether the heart scan had been performed after exposure to air or a mixture of $\mathrm{CO}$ and air. Blood was drawn for lactic and pyruvic acid at the beginning and the end of the exercise test. SIGMA kits were used for spectrophotometric measurement of lactate and pyrovate.

STATISTICAL ANALYSIS

Duration of the exercise test and the maximal effort expressed in METs were fitted with a linear model by the method of least squares with preparation, period, sequence, and volunteer nested within sequences as independent variables. The sequence effect was tested with the volunteer (sequence) mean square from the ANOVA as an error term. All other main effects were tested against the residual error from the ANOVA. The least squares means were used to calculate least square mean for treatment (adjusted).

Residual plots against predicted values were done for all models. The distributions of the residuals were computed. The Shapiro-Wilk statistics were used to test the hypothesis that the residuals are a random sample from a normal distribution.

The computation was performed by SAS 6.12 software.

\section{Results}

The average age of the 15 subjects was 26 years (range 22-34 years). Mean (SD) blood concentrations of $\mathrm{COHb}$ before and after exposure to air were similar $(0.51 \%(0.12 \%)$ and $0.54 \%$ $(0.06 \%)$ respectively). At the end of exposure to $\mathrm{CO}$, the mean (SD) blood concentration rose from $0.59(0.08 \%)$ to $5.1(0.65 \%)$ $(\mathrm{p}<0.0001)$. The mean (SD) lactic and pyruvic acid values in the group exposed to air were 1.6 (0.22) $\mathrm{mmol} / \mathrm{l}$ and 0.06 (0.006) $\mathrm{mmol} / \mathrm{l}$ respectively before, and $14.9(1.2) \mathrm{mmol} / \mathrm{l}$ and $0.23(0.03) \mathrm{mmol} / \mathrm{l}$ at the end of the exercise test (table 1). After exposure to $\mathrm{CO}$, the mean (SD) concentration of lactic acid was 1.6 (0.15) $\mathrm{mmol} / \mathrm{l}$ and of pyruvic acid $0.04(0.004)$ $\mathrm{mmol} / \mathrm{l}$ before the exercise test, and 12.5 (1.1) $\mathrm{mmol} / \mathrm{l}$ and $0.18(0.017) \mathrm{mmol} / \mathrm{l}$ respectively at the end (table 1). At the end of the exercise period, the mean plasma lactate/pyruvate ratio, which reflects the level of anaerobic metabolism (69.9 (5.9) after air and 75.9 (7.0) after $\mathrm{CO}$ ), was not significantly different among the two experimental groups (table 1). There was no significant difference between the mean heart rate and blood pressure before and after exposure to air or CO. There were also no significant differences in peak heart rate (189 (2) and 186 (2) in the air and CO groups, respectively) or blood pressure (161/77 and 154/75 in air and $\mathrm{CO}$ groups, respectively) after the 
Table 2 Carboxyhaemoglobin after exposure to $C O$, and exercise test data for all subjects

\begin{tabular}{|c|c|c|c|c|c|c|}
\hline Subject No & $\begin{array}{l}\text { METS After CO } \\
\text { exposure }\end{array}$ & $\begin{array}{l}\text { METS after air } \\
\text { exposure }\end{array}$ & $\begin{array}{l}\text { Exercise duration } \\
\text { after } C O\end{array}$ & $\begin{array}{l}\text { Exercise duration } \\
\text { after air }\end{array}$ & $\begin{array}{l}\text { CoHb concentrati } \\
\text { on after CO } \\
\text { exposure }\end{array}$ & $\begin{array}{l}\text { CoHb concent } \\
\text { ration before } C O \\
\text { exposur e }\end{array}$ \\
\hline 1 & 14 & 17 & $13: 30$ & $15: 25$ & 3.8 & 0 \\
\hline 2 & 16 & 18 & $14: 39$ & $16: 24$ & 2.9 & 0.3 \\
\hline 3 & 15 & 18 & $13: 49$ & $17: 00$ & 5.2 & 0.3 \\
\hline 4 & 17 & 22 & $15: 20$ & $20: 00$ & 8.0 & 0.7 \\
\hline 5 & 16 & 17 & $14: 31$ & $15: 06$ & 5.7 & 0.9 \\
\hline 6 & 15 & 16 & $14: 04$ & $14: 03$ & 5.9 & 0.9 \\
\hline 7 & 17 & 18 & $15: 55$ & $16: 44$ & 4.6 & 0.7 \\
\hline 8 & 10 & 14 & $11: 48$ & $12: 57$ & 2.3 & 0.8 \\
\hline 9 & 17 & 18 & $15: 01$ & $16: 08$ & 4.5 & 0.6 \\
\hline 10 & 13 & 14 & $12: 24$ & $13: 00$ & 5.8 & 0.3 \\
\hline 11 & 12 & 14 & $10: 54$ & $12: 31$ & 4.5 & 0.7 \\
\hline 12 & 12 & 13 & $11: 33$ & $12: 24$ & 8.9 & 1.2 \\
\hline 13 & 19 & 22 & $17: 16$ & $20: 28$ & 4.2 & 0.6 \\
\hline 14 & 14 & 15 & $13: 53$ & 13:01 & 5.4 & 0.4 \\
\hline 15 & 15 & 17 & $14: 01$ & $15: 05$ & 5.1 & 0.5 \\
\hline Mean (SD) & $14.8(0.6)$ & $16.9(0.7)$ & $13: 70(0.4)$ & $15: 40(0.6)$ & $5.12(0.65)$ & $0.59(0.08)$ \\
\hline
\end{tabular}

maximal exercise test. Exercise induced electrocardiographic changes (ST depression on leads I, aVL, V5, V6) were noted in only one subject after exposure to $\mathrm{CO}$. This subject was asymptomatic during the exercise test, and stopped running due to fatigue. No arrhythmias were detected in any of the subjects.

The data on the exercise duration and METs during exposure to air or $\mathrm{CO}$ from all subjects are presented in table 2. The model for maximal effort expressed in METs showed no significant sequence effect $(\mathrm{p}=0.4)$ and no significant period effect $(\mathrm{p}=0.34)$.

A significant difference between METs in air and $\mathrm{CO}$ was found $(\mathrm{p}=0.0001)$. The mean adjusted MET in air was 16.9 (95\% confidence interval $(95 \% \mathrm{CI}) 16.4$ to 17.4$)$. The mean adjusted MET in CO was 14.8 (95\% CI 14.3 to 15.4$)$. The mean adjusted difference in the METs between exposure to air and $\mathrm{CO}$ was $2.0495 \%$ CI (1.33 to 2.76 ).

The model for exercise duration showed no significant sequence effect $(p=0.35)$ and no significant period effect $(p=0.69)$. A significant difference in exercise duration on exposure to air and CO was found $(\mathrm{p}=0.0012)$. The mean adjusted exercise duration in air was 15.3 (95\% CI 14.7 to 15.9$)$ minutes. The mean adjusted exercise duration in CO was 13.7 (95\% CI 13.2 to 14.3 ). The mean adjusted difference of exercise duration between exposure to air and CO was 1.52 minutes (95\% CI 0.73 to 2.32).

Thallium myocardial perfusion imaging disclosed normal perfusion in all regions of the heart, with no significant differences in perfusion between the two exercise tests (after air or $\mathrm{CO})$.

\section{Discussion}

Carbon monoxide affects the heart mainly by inducing tissue hypoxia. ${ }^{1}$ It has a very high affinity for haemoglobin, with which it binds firmly to form $\mathrm{COHb}$. This results in a marked decrease in the oxygen carrying capacity of haemoglobin and a leftward shift of the oxyhaemoglobin dissociation curve, which reduces the release of oxygen to tissues. ${ }^{15}{ }^{16}$ At the cellular level, CO binds with cytochrome oxidase, inhibiting cellular respiration and resulting in anaerobic metabolism. ${ }^{17}$ Carbon monoxide also binds with other haemoproteins such as myoglobin, which abounds in skeletal muscles and the myocardium, causing dysfunction by impairing their oxygen carrying capacity and the transportation of oxygen from the blood to the mitochondria. ${ }^{18}$

Carbon monoxide is the leading cause of death by poisoning. It is colourless, odourless, tasteless, and non-irritating, which makes its presence difficult to detect. The signs and symptoms of $\mathrm{CO}$ poisoning are non-specific, and usually appear when $\mathrm{COHb}$ concentrations are above $10 \%$. Recent data suggest that exposure to low concentrations of CO have a direct adverse effect on the heart, exacerbating myocardial ischaemia and facilitating ventricular arrhythmias in patients with coronary heart disease.$^{3-6}$ Such data are pertinent to industrial and inner city areas, where many people are exposed daily to air pollution sufficient to produce chronically increased blood $\mathrm{COHb}$ concentrations in the range used in our study. ${ }^{2} \mathrm{By}$ contrast with previous studies on the effects of low concentrations of $\mathrm{COHb}$ on patients with ischaemic heart disease ${ }^{3-6}$ only few studies considered this issue in normal healthy subjects, with controversial results. Turner and $\mathrm{McNicol}^{19}$ did not find a significant effect on cardiovascular performance of exposure to $\mathrm{CO}$ whereas Aronow and Cassidy ${ }^{20}$ found that increased $\mathrm{COHb}$ concentrations impair exercise performance in 10 normal middle aged men. Neither one of them found ischaemic electrocardiographic changes during exercise. In the light of these controversial data on a normal population with no data on young healthy subjects we decided to study the effects of low blood concentrations of $\mathrm{COHb}$ on the capacity to perform maximal exercise and on myocardial perfusion in young, healthy nonsmoking men.

We used the blood lactate/pyruvate ratio as an index of anaerobic metabolism. When this ratio is high ( $>40-50)$, anaerobic metabolism is considerable. ${ }^{21}$ The high lactate/pyruvate ratio recorded after exposure to both air and $\mathrm{CO}$ indicates that the subjects did indeed attain maximal effort. There was no significant difference in anaerobic metabolism after exposure to $\mathrm{CO}$. The apparent contradiction between this finding and the significant decrease in exercise duration after $\mathrm{CO}$ may be explained by the assumption that exposure to CO lowers the anaerobic threshold. Indeed, 
Koike et $a l^{2}$ reported that during exercise both lactate concentration and lactate/pyrovate ratio increase only after the anaerobic threshold is reached. They also showed that increased $\mathrm{COHb}$ concentration decreased the metabolic acidosis threshold (anaerobic threshold). As a result, the transition to anaerobic metabolism may appear earlier, causing early fatigue of skeletal muscles and decreased maximal effort capability, but with no effect on the final concentration of lactic and pyruvic acid in the blood which reflect the fact that subjects reached their maximal effort capacity.

Ischaemic changes on exercise testing after exposure to $\mathrm{CO}$ were found in only one subject, but thallium scanning was normal in all of them. The electrocardiographic changes in one subject may be regarded as a false positive result, based on the fact that false positive findings are detected in exercise tests in up to $15 \%$ of young men. ${ }^{23}$ This interpretation is supported by the fact that the subject was asymptomatic and his thallium scans were normal.

The salient findings in this study were the significant decrease in exercise duration and maximal effort capability after exposure to CO. In 13 of the 15 subjects, effort was maintained for a shorter time, and in all of them the degree of maximal effort measured in METs was lower after exposure to CO.

In the urban environment, many people are chronically exposed to considerable air pollution, which produces blood concentrations of $\mathrm{COHb}$ between $2 \%$ and $6 \%$, as is the case with many smokers. Such concentrations of $\mathrm{COHb}$ not only exacerbate myocardial ischaemia in patients with coronary artery disease, but as suggested by our data also exert a detrimental effect on the exercise performance of young healthy men. Also, smokers chronically exposed to air pollution may have higher blood concentrations of $\mathrm{COHb}$, and therefore a more severe threat to their health.

In conclusion, we found that acute exposure to low concentrations of $\mathrm{CO}$ which produces blood $\mathrm{COHb}$ concentrations of $4 \%-6 \%$ significantly decreases exercise performance in young healthy men. No ischaemic electrocardiographic changes or disturbances in myocardial perfusion were found by graded exercise and thallium scintigraphy. Our findings suggest that pollution of the atmospheric air by $\mathrm{CO}$ may have adverse effects on skeletal muscles, causing decreased exercise performance. This reinforces the need for tighter restrictions and controls on atmospheric air pollution.
This study was supported by a grant from the Committee for Research and Prevention in Occupational Safety and Health, Ministry of Labour and Social Affairs, Israel. We thank Dr A Laor for his help in the design of the study and the statistical analysis.

1 Stewart RD. The effect of carbon monoxide on humans. $\mathcal{F}$ Occup Med 1976;18:304-9.

2 Walden SM, Gottlieb SO. Urban angina, urban arrhythmias: carbon monoxide and the heart. Ann Intern Med 1990;113:337-8.

3 Anderson EW, Andelman RJ, Strauch JM, et al. Effect of low-level carbon monoxide exposure on onset and duration of angina pectoris. A study in 10 patients with ischemic heart disease. Ann Intern Med 1973;79:46-50.

4 Aronow WS, Isbell MW. Carbon monoxide effect on exercise-induced angina pectoris. Ann Intern Med 1973;79: $392-5$.

5 Allred EN, Bleecker ER, Chaitman BR, et al. Short-term effects of carbon monoxide exposure on the exercise performance of subjects with coronary artery disease. $N$ Engl f Med 1989;321:1426-32.

6 Sheps DS, Herbst MC, Hinderliter AL, et al. Production of arrhythmias by elevated carboxyhemoglobin in patients with coronary artery disease. Ann Intern Med 1990;113: 343-51.

7 Stern FB, Halperin WE, Hornung RW, et al. Heart disease mortality among bridge and tunnel officers exposed to carbon monoxide. Am 7 Epidemiol 1988;128:1276-88.

8 Peterson JE, Stewart RD. Absorption and elimination of carbon monoxide by inactive young men. Arch Environ Health 1970;21:165-71.

9 Stewart RD, Peterson JE, Baretta ED, et al. Experimental human exposure to carbon monoxide. Arch Environ Health 1970; 21:154-64.

10 Froelicher VF, Myers J, Follansbee WP, et al. Exercise and the heart, 3rd ed. Mosby-year book. St Louis: Mosby, 1993.

11 Robert JM, Sullivan M, Froelicher VF, et al. Predicting oxygen uptake from treadmill testing in normal subjects and con uptake from treadmill testing in normal subjects and coronary

12 Kiat H, Maddahi J, Roy LT, et al. Comparison of technetium $99 \mathrm{~m}$ methoxy isobutyl isonitrile and thallium 201 for evaluation of coronary artery disease by planar and tomographic methods. Am Heart f 1989;117:1-11.

13 Iosilevsky G, Israel O, Frenkel A, et al. A practical SPECT technique for quantitation of drug delivery to human tumors and organ absorbed radiation dose. Semin Nucl Med 1989;19:33-46.

14 Garcia EV, Van Train K, Maddahi J, et al. Quantification of rotational thallium-201 myocardial tomography. $\mathcal{F}$ Nucl Med 1985;26:17-26

15 Douglas CG, Haldane JS, Haldane JBS. The laws of combination of haemoglobin with carbon monoxide and oxygen. F Physiol 1912;44:275-304.

16 Roughton FJW, Darling RC. Effect of carbon monoxide on oxyhemoglobin dissociation curve. Am f Physiol 1944;141: $17-31$.

17 Chance B, Erecinska M, Wagner M. Mitochondrial responses to carbon monoxide toxicity. Ann N Y Acad Sci 1970;174:193-204.

18 Caughey WS. Carbon monoxide bonding in hemeproteins. Ann N Y Acad Sci 1970;174:148-53.

19 Turner JA, McNicol MW. The effect of nicotine and carbon monoxide on exercise performance in normal subjects. Respir Med 1993;87:427-31.

20 Aronow WS, Cassidy J. Effect of carbon monoxide on maximal treadmill exercise. A study in normal persons. Ann Intern Med 1975;83:496-9.

21 Wasserman K, Hansen JE, Sue DY, et al. Principles of exercise testing and interpretation. Philadelphia: Lea and Febiger, 1987:6-13.

22 Koike A, Weiler-Ravell D, McKenzie DK, et al. Evidence that the metabolic acidosis threshold is the anaerobic threshold. F Appl Physiol 1990;68:2521-6.

23 Wilson JD, Braunwald $\mathrm{E}$, Isselbacher $\mathrm{KJ}$, et al, eds. Harrison's principles of internal medicine, 12th ed. New York: McGraw-Hill, 1991:102. 